\title{
A importância do lúdico nas aulas de educação física no processo de ensino aprendizagem nas séries iniciais
}

O lúdico no processo ensino-aprendizagem contribui significativamente no desenvolvimento físico, afetivo, social e cognitivo, auxilia na prática do professo proporcionando aos educandos uma aprendizagem de qualidade. Este artigo procurou compreender a importância do lúdico no processo de ensino aprendizagem nas aulas de Educação Física nas séries iniciais. Para isso desenvolveu uma pesquisa de revisão bibliográfica de abordagem qualitativa, tendo em vista colher opiniões, concepções e explicações fazendo uma reflexão em torno do assunto. Diante as concepções dos autores sobre o saber da criança por meio do brincar, vimos que este contribui de forma harmoniosa e significativa para o desenvolvimento das habilidades e capacidades do aluno no contexto educacional, favorecendo através da mediação do professor a criticidade e autonomia dos alunos. Relação de reciprocidade entre professor e aluno é necessário para resolver situações presentes no cotidiano escolar nas aulas de Educação Física. Considera-se com este trabalho, que é importante utilizar o lúdico na prática docente.

Palavras-chave: Lúdico; Aprendizagem; Brincadeiras

\section{The importance of playfulness in physical education classes in the teaching-learning process in the early grades}

Playfulness in the teaching-learning process contributes significantly to physical, affective, social and cognitive development, assists in the practice of the teacher providing students with quality learning. This article sought to understand the importance of playfulness in the teaching-learning process in Physical Education classes in the early grades. For this, he developed a literature review research with a qualitative approach, in order to collect opinions, concepts and explanations by reflecting on the subject. In view of the authors 'conceptions about the child's knowledge through playing, we saw that it contributes in a harmonious and significant way to the development of the student's skills and abilities in the educational context, favoring through the teacher's mediation the students' criticality and autonomy. A reciprocal relationship between teacher and student is necessary to resolve situations present in the school routine in Physical Education classes. With this work, it is considered that it is important to use playfulness in teaching practice.

Keywords: Ludic; Learning; Jokes.

Topic: Formação e Qualificação do Professor

Reviewed anonymously in the process of blind peer
Received: 06/01/2020

Approved: 21/04/2020
Marcos Antônio Araújo Bezerra (iD

Centro Universitário Dr. Leão Sampaio, Brasil

http://lattes.cnpq.br/4643352879633283

http://orcid.org/0000-0002-3385-4024

marcosantonio@leaosampaio.edu.br

Hellen Karen Dório da Silva (id

Centro Universitário Vale do Salgado, Brasil

http://lattes.cnpq.br/2973705929429734

http://orcid.org/0000-0001-6591-4004

hellenkarendorio@gmail.com

Gabriela Gomes de Oliveira Bezerra

Centro Universitário Dr. Leão Sampaio, Brasil

http://lattes.cnpq.br/6330341118187369

http://orcid.org/0000-0002-9724-708X

gabriela.o.bezerra@gmail.com
José de Caldas Simões Neto (iD

Centro Universitário Dr. Leão Sampaio, Brasil

http://lattes.cnpq.br/0470733825644726

http://orcid.org/0000-0003-1036-2315

josecaldas@leaosampaio.edu.b

\section{Renan Costa Vanali}

Centro Universitário Dr. Leão Sampaio, Brasil

http://lattes.cnpq.br/0464534899158947

http://orcid.org/0000-0002-4193-3363

renan@leaosampaio.edu.br
Referencing this:

BEZERRA, M. A. A.; SILVA, H. K. D.; BEZERRA, G. G. O.; SIMÕES NETO, J. C.; VANALI, R. C.. A importância do lúdico nas aulas de educação física no processo de ensino aprendizagem nas séries iniciais. Humanum Sciences, v.2, n.1, p.18-24, 2019. DOI:

http://doi.org/10.6008/CBPC2674-6654.2020.001.0003 


\section{INTRODUÇÃO}

Desde o seu nascimento o homem tem a necessidade de aprender, pois através do conhecimento ele se humaniza, integrando-se na sociedade. Durante a fase infantil o brincar predomina como algo fundamental para criança e privá-la desse momento pode acarretar vários problemas emocionais, sociais, e cognitivos o que pode interferir no seu desenvolvimento (SILVA et al., 2016).

Por meio da brincadeira, a aprendizagem se torna muito mais significativa e segundo Silva (2011), vários fatores como a cognição, o equilíbrio, os impulsos e a compreensão de mundo são desenvolvidas nas atividades lúdicas. Para Arantes et al. (2017), as brincadeiras são ferramentas que permitem a criança expressa-se, demonstrando sentimentos, interesses e desinteresses, realidades, habilidades e capacidades.

Nessa direção, Afonso et al. (2013) afirmam:

É justamente a capacidade de brincar que permite o questionamento, a desconstrução de sentidos cristalizados e a invenção de novos sentidos diante da realidade social já simbolizada através das mais diferentes formas. É a capacidade de brincar - e o imaginário, como seu correlato - que permite o desenvolvimento do pensamento para além das fronteiras do que já está historicamente dado.

Conforme Anjos (2013), a ludicidade através das brincadeiras é um ótimo meio de impulsionar e auxiliar a aprendizagem de diferentes áreas agindo de forma multidisciplinar, pois ela está integrada ao conhecimento obtido da realidade e a associação de tudo que se almeja. Uma vez que o papel do professor é cooperar para que o ensino-aprendizagem seja verdadeiramente transformador, principalmente nos aspectos de formação do caráter lúdico do aluno.

Através da ludicidade e situações vivenciadas nas aulas de Educação Física são dadas oportunidades à criança de se relacionar melhor com pessoas e com o meio. Ela aprende com mais prazer, tranquilidade, flexibilidade, o que permite o desenvolvimento dos níveis de aprendizagem com mais significação (MALAQUIAS et al., 2013).

Como suporte na prática do professor, que contribuição a ludicidade proporciona ao aluno das séries iniciais no processo de ensino aprendizagem nas aulas de Educação Físicas?. Os alunos enquanto crianças acolhem muito bem a disciplina Educação Física. Assim, Modesto et al. (2014) asseguram que o aspecto lúdico é um importante meio na concentração, desenvolvimento pessoal, cultural e social da criança, já que os sonhos infantis se mesclam com a realidade.

As atividades físicas permitem aumentar uma série de possibilidades educativas utilizadas para um saber fixo melhorando significativamente o aprendizado. Pensando nisso, este artigo tem como finalidade compreender conceitos que abrangem a ludicidade, a importância do lúdico e do professor de Educação Física no desenvolvimento da sua práxis.

\section{METODOLOGIA}

Trata-se de um estudo de cunho qualitativo, do tipo revisão bibliográfica, realizado nos portais de periódicos Scielo e google acadêmico, se utilizando dos descritores: lúdico, aprendizagem, brincadeiras, entre tendo em vista colher opiniões dos autores, concepções, fazendo uma reflexão em torno do assunto, 
objetivando compreender a relevância que a ludicidade tem no ensino e na aprendizagem das aulas de Educação Física das séries iniciais.

\section{RESULTADOS E DISCUSSÃO}

\section{Definições do lúdico}

O lúdico segundo Anjos (2013), se originou da palavra "ludus" que significa jogo, ele evoluiu ganhando novas considerações principalmente pelas pesquisas abrangendo a psicomotricidade, por essa razão passou a ter outros significados e não somente o sentido de jogo. Toda e qualquer atividade que desenvolva a criatividade, a habilidade e o potencial do indivíduo, além de despertar e estimular a sua imaginação são consideradas lúdicas. Definem-se como lúdico, os jogos, as brincadeiras, todas de grande relevância no que diz respeito a cognição e a afetividade da criança.

Pode ser complexa a tarefa de definir a palavra jogo, devido a sua amplitude de especificidades, uma vez que a designação jogo pode ter definições conforme a concepção de cada contexto social. Assim, dependendo da época ou lugar o jogo ganha roupagens distintas caracterizado pela cultura e sempre de acordo com os novos contextos, variando segundo a linguagem e a vivência social inserido em um conjunto de regras (KISHIMOTO, 2006).

Para Maluf (2009):

O jogo carrega em si um significado muito abrangente. Ele tem uma carga psicológica, porque é revelador da personalidade do jogador (a pessoa vai se conhecendo enquanto joga). Ele tem também uma carga antropológica, porque faz parte da criação cultural de um povo (resgate e identificação com a cultura).

Segundo Nallin (2005) a brincadeira "[...] é a atividade mais típica da vida humana, por proporcionar alegria, liberdade e contentamento. É a ação que a criança desempenha ao concretizar as regras do jogo e ao mergulhar na ação lúdica. Pode-se dizer que é o lúdico em ação". A realização da brincadeira não surge para a criança como planejamento, compromisso e seriedade, mas, imaginação e divertimento.

A inteligência é incitada pelo brincar, fazendo com que a imaginação do sujeito seja liberada e sua criatividade seja desenvolvida, propiciando o exercício da atenção, concentração e do engajamento, e dessa forma, possibilitando motivação e desafios (OLIVEIRA et al., 2017). Portanto, fica evidente que através do brincar, a criança satisfaz as suas necessidades, estruturando-se, conforme a sua consciência vai se transformando.

\section{A importância do lúdico no processo de ensino aprendizagem}

O lúdico deve fazer parte do ambiente escolar, no tocante à aprendizagem dos alunos, pois através do brincar, a criança se desenvolve com mais desempenho e naturalidade (ANJOS, 2013). Um importante método para o professor interessado em gerar mudanças em sua prática docente, pode ser encontrado na proposta do lúdico, que poderá colaborar na diminuição dos altos números tanto de fracasso escolar, quanto de evasão escolar, observados nas escolas, ao transcorrer das séries iniciais, sendo minimizadas consideravelmente as chances do aluno fracassar ou abandonar a escola, ao se apropriar do conhecimento 
(OLIVEIRA et al., 2017).

Segundo Bueno (2010) “[...] é através das ações, do fazer, pensar e brincar, que o ser humano vai construir seu conhecimento e desenvolver suas estruturas psíquicas para se relacionar com o mundo concreto". Ainda segundo Bueno (2010) "as brincadeiras se constituem como lazer e ensinamento para a própria criança, porque é justamente por meio delas que as crianças podem discernir situações, resolvê-las e aprender ao mesmo tempo".

Conforme Anjos (2013), a inserção do lúdico no cotidiano escolar é um meio de levar o aluno a construir suas próprias características individuais para que tenham assim uma boa personalidade e que possam ter uma boa participação na sociedade. Ressalta-se os benefícios que o lúdico traz aos estudantes, de forma a contribuir para o seu desenvolvimento no ensino aprendizagem. A esse respeito, Aguiar (1998) esclarece

A atividade lúdica é reconhecida como meio de fornecer à criança um ambiente agradável, motivador, planejado e enriquecido, que possibilita a aprendizagem de várias habilidades, além de trabalhar estas habilidades na criança, ajudará no desenvolvimento da criatividade, na inteligência verbal-linguística, coordenação motora, dentre outras. Partindo da consideração de que as atividades lúdicas podem contribuir para o desenvolvimento Intelectual da criança, Platão ensinava matemática às crianças em forma de jogo e preconizava que os primeiros anos da criança deveriam ser ocupados por jogos educativos.

Conforme os Parâmetros Curriculares Nacionais de 1997 (PCNs), a criança ao entrar na escola deve participar de atividades de Educação Física que aprimore suas habilidades corporais, envolvendo-a em atividades culturais, como jogos, danças, etc.. Eles ainda fazem referência às peculiaridades individuais e as experiências prévias do aluno ao se deparar com diferentes situações que compõem o ponto de partida para o aprendizado.

Em todos os componentes curricular, os jogos, e as brincadeiras são muito usados de acordo com a criatividade de cada profissional e segundo Ribeiro et al. (2011) o professor deve "possuir característica básica de observação, ter olhos e ouvidos bem atentos e sensibilidade para perceber as necessidades de seus alunos". Cabe ao professor inovar sempre a sua prática pedagógica, pois, o conhecimento é totalmente essencial na atualidade.

Oliveira et al. (2017) asseguram que o aluno, por meio dos jogos e das brincadeiras explora ainda mais a sua criatividade, aprimorando seu comportamento e sua autoestima no processo ensinoaprendizagem, mas para que os jogos não se tornem atividade dirigida e manipuladora, o educador deve ter cautela ao utilizá-los com fins pedagógicos. Caso contrário, o jogo perderá o sentido de liberdade e espontaneidade. $O$ professor ao fazer uso dos jogos e brincadeiras deve traçar objetivos definidos para se chegar ao um resultado satisfatório de forma prazerosa. Ao incorporar na aprendizagem a ludicidade, podem-se dizer que ela favorece novas e interessantes relações e interações das crianças entre si e destas com o conhecimento.

Se os professores trabalhassem em suas práticas a ludicidade de forma ativa, estaria oportunizando ao estudante estudar com prazer no processo de conhecer, como também, descobrindo com eles novas maneiras de ensinar e de aprender. O lúdico como suporte pedagógico proporciona ao educando uma 
aprendizagem mais significativa, promovendo a formação de cidadãos menos individualistas, mais críticos e participativos.

\title{
O papel do professor nas aulas de Educação Física no processo de ensino aprendizagem
}

O professor é o principal mediador no desenvolvimento da aprendizagem. Segundo Silva et al. (2016), cabe a este criar um ambiente acolhedor, se utilizando de mecanismos que facilitem a assimilação dos conteúdos pelos alunos. A brincadeira por fazer parte da criança, possibilitará a esta vivenciar o que está sendo estudado. Para Lira et al. (2014), as relações de intimidades entre o brincar e a criança, favorece o seu desenvolvimento social, afetivo e cognitivo, e como forma de cultura e atividade biológica fundamental e espontânea da criança, o brincar, de geração a geração, transmite e acrescenta sabedoria e valores.

A Educação Física possui uma grade de conteúdo para cada ciclo, independente de que esteja incumbido de ministrá-la, que a faça bem e de forma lúdica. De acordo com PCNs:

\begin{abstract}
As situações lúdicas, competitivas ou não, são contextos favoráveis de aprendizagem, pois permitem o exercício de uma ampla gama de movimentos que solicitam a atenção do aluno na tentativa de executá-los de forma satisfatória e adequada. Elas incluem, simultaneamente, a possibilidade de repetição para manutenção e por prazer funcional e a oportunidade de ter diferentes problemas a resolver. Além disso, pelo fato de o jogo constituir um momento de interação social bastante significativo, as questões de sociabilidade constituem motivação suficiente para que o interesse pela atividade seja mantido. (BRASIL, 1997).
\end{abstract}

A Educação Física é vista como componente predominantemente prática, sendo, consequentemente, marcada por uma compreensão hegemônica, e quase que excepcionalmente associando-a à prática de exercícios físicos, esportivos, e brincadeiras, entendendo-a somente pela sua dimensão prática, pertinente ao movimento humano, porém, sem relacioná-la adequadamente com a especificidade da educação escolar e da natureza (COSTA et al., 2016).

As aulas de Educação Física nas séries iniciais são ministradas por docentes dos cursos de Pedagogia e curso Normal. É necessário que essa disciplina seja desenvolvida de maneira correta, evitando a realização de atividades com jogos aleatórios que buscam somente o lazer das crianças (COSTA, 2014). Os professores precisam estar aptos para ministrarem aulas, bem como exercícios que sejam apropriadas à idade da criança, priorizando o seu desenvolvimento pleno (MOURA, 2013).

Nessa perspectiva, o uso do lúdico nas atividades propostas, oportuniza ao educando, independente da classe social, seu saber, seu conhecimento. Para Costa (2014), no decorrer das aulas atuais de Educação Física, habilidades e competências são desenvolvidas, de forma a promover um relacionamento comunitário, a escutar, a partilhar e a trocar experiências entre professor e aluno.

O professor ao planejar suas aulas, sejam elas dentro ou fora do ambiente escolar, deve partir de uma postura reflexiva, buscando alcançar os objetivos estabelecidos por meio de atividades, procedimentos e estratégias coerentes com a realidade dos alunos, para que juntos, professor e aluno, possam enfrentar as dificuldades durante o ensino, melhorando assim, os resultados obtidos pelos educandos (SILVA et al., 2016). É importante que a criança tenha liberdade para criar suas próprias brincadeiras, pelo uso de cordas, bolas, ou de seu próprio corpo, correndo e saltando. Contudo, este fato não deve configurar um ato de abandono 
pedagógico, pois a intervenção do professor se faz necessária no processo educativo da criança (COSTA, 2014).

A criança tem muito a ensinar aos professores em relação ao brincar. O professor deve aprender com seu aluno, e não se sentir o 'dono da verdade'. Na vivência da aprendizagem da criança, há experiências que devem ser englobadas de forma positiva. As barreiras criadas pelo professor devem ser rompidas. Especialmente os educadores mais experientes, devem se "aventurar" no universo infantil. Contudo, deve haver a reciprocidade entre professor e aluno (VIEIRA et al., 2016).

\section{CONCLUSÕES}

Este artigo teve como objetivo discorrer sobre a importância do lúdico na aprendizagem da criança durante o processo de ensino nas séries iniciais. O saber da criança por meio do brincar vai se construindo à medida que ela vai crescendo, o que contribui no contexto educacional para o desenvolvimento das habilidades e capacidades do aluno de forma harmoniosa e significativa.

Durante todo o processo de ensino nas séries iniciais, deve-se promover atividades diversificadas que exerçam nos educandos estímulos positivos frente aos aspectos cognitivo, físico e afetivo para que a sua atuação dentro ou fora do ambiente escolar promova o seu desenvolvimento pleno. A importância da mediação do professor diante as situações presentes no cotidiano escolar nas aulas de Educação Física se fazem necessária para a criticidade e autonomia dos alunos. Conclui-se, portanto, que o lúdico é relevante na prática docente, por estabelecer entre o professor e o aluno uma relação recíproca de trocas de saberes.

\section{REFERÊNCIAS}

AFONSO, M. L. M.; ABADE, F. L.. Jogos para pensar:

Educação em Direitos Humanos e Formação para a

Cidadania. Belo Horizonte: Autêntica, 2013.

AGUIAR, J. S.. Jogos para o ensino de conceitos. Campinas: Papirus, 1998.

ANJOS, J. A.. A importância das atividades lúdicas nas aulas de educação física no processo ensino aprendizagem. Monografia (Especialização em Educação Física Educação a Distância) - Universidade de Brasília, Ariquemes, 2013.

ARANTES, A. R. V.; BARBOSA, J. T. S.. O lúdico Na Educação Infantil. Revista Online de Magistro de Filosofia, v.10, n.21, p.100-115, 2017.

BRASIL. Parâmetros Curriculares Nacionais. Apresentação dos temas transversais e ética. Brasília: MEC, 1997.

BUENO, E.. Jogos e Brincadeiras na educação infantil: ensinando de forma lúdica. Monografia (Bacharelado em Pedagogia) - Universidade Estadual de Londrina, Londrina, 2010.

COSTA, E. C.. A Educação Física nos anos iniciais do ensino fundamental: a aula é proporcionada? Por quem? O que se desenvolve e o que realmente se deve desenvolver?.

Efdeportes.com: Revista Digital, Buenos Aires, v.18, n.190, p.1-1, 2014
COSTA, J. B.; MIRANDA, F. S. B.; LAVOURA, T. N.. Atividade de ensino da Educação Física e a Formação do Pensamento Teórico. Psicologia da Educação, São Paulo, n.42, p 71-80, 2016.

KISHIMOTO, T. M.. Jogo, brinquedo, brincadeira e a educação. 9 ed. São Paulo: Cortez, 2006.

LIRA, N. A. B.; RUBIO, J. A. S.. A importância do brincar na Educação Infantil. Revista Eletrônica Saberes da Educação, São Roque, v.5, n.1, p.1-22, 2014.

MALAQUIAS, M. S.; RIBEIRO, S. S.. A Importância do Lúdico no Processo de Ensino-Aprendizagem no Desenvolvimento da Infância. Psicologado, 2013.

MALUF, A. C. M.. Brincar: prazer e aprendizado. 7 ed. Petrópolis: Vozes, 2009.

MODESTO, M. C.; RUBIO, J. A. S.. A importância da Ludicidade na construção do conhecimento. A Importância da Ludicidade na Construção do Conhecimento. Revista Eletrônica Saberes da Educação, São Roque, v.5, n.1, p.1-16, 2014.

MOURA, S.. A importância da Educação Física nos anos iniciais. Centro Esportivo Virtual, 2013. 
NALLIN, C. G. F.. Memorial de Formação: o papel dos jogos e brincadeiras na Educação Infantil. Campinas, 2005.

OLIVEIRA, C. M.; DIAS, A. F.. A Criança e a Importância do Lúdico na Educação. Revista Científica Multidisciplinar Núcleo do Conhecimento, v.2, v.13, p.113-128, 2017.

RIBEIRO, K. L.; SOUZA, S. P.. Jogos na Educação Infantil. Serra: Escola Superior de Ensino Anísio Teixeira, 2011.

SILVA, A. P.; LIMA, A. F. S.; SILVA, H. D.; MARTINUSSI, V. S.; PICELLI, L. A.. A importância do lúdico nas séries iniciais.
Revista da Educação, Umuarama, v.16, n.2, p.209-218, 2016 DOI: http://doi.org/10.25110/educere.v16i2.2016.5969

SILVA, V. N.. A Contribuição do Brincar como Recurso Pedagógico na Sala de Alfabetização da Escola Milton da Costa Ferreira. Revista Científica de Ciências Sociais Aplicadas da EDUVALE, Jaciara, v.4, n.6, 2011.

VIEIRA, L. B.; RODRIGUES, E. A. F.. O Ensino Lúdico Nos Anos Iniciais. Revista Científica Multidisciplinar Núcleo do Conhecimento, v.10, n.11, p.136-153, 2016.

A CBPC - Companhia Brasileira de Produção Científica (CNPJ: 11.221.422/0001-03) detém os direitos materiais desta publicação. Os direitos referem-se à publicação do trabalho em qualquer parte do mundo, incluindo os direitos às renovações, expansões e disseminações da contribuição, bem como outros direitos subsidiários. Todos os trabalhos publicados eletronicamente poderão posteriormente ser publicados em coletâneas impressas sob coordenação da Sapientiae Publishing, da Companhia Brasileira de Produção Científica e seus parceiros autorizados. Os (as) autores (as) preservam os direitos autorais, mas não têm permissão para a publicação da contribuição em outro meio, impresso ou digital, em português ou em tradução. 